\title{
Dietary Omega-3 Intakes in Southern African American and Southern Caucasian Women
}

Myers $\mathrm{KB}^{{ }_{1}}$, Goad $\mathrm{TN}^{1}$, Cox $\mathrm{JJ}^{2}$, Hickner $\mathrm{RC}^{2,4,5,6}$, Ivanescu $\mathrm{AE}^{3}$, Wheeler $\mathrm{M}^{1}$ and Cortright $\mathrm{RN}^{2,5}$

${ }^{1}$ Department of Nutrition Science, College of Human Ecology, East Carolina University, Greenville, NC, USA

${ }^{2}$ Human Performance Laboratory, Department of Kinesiology, College of Health and Human Performance and Department of Physiology, Brody School of Medicine, East Carolina University, Greenville, NC, USA

${ }^{3}$ Department of Biostatistics, College of Allied Health Sciences, East Carolina University, Greenville, NC, USA

${ }^{4}$ Center for Health Disparities, East Carolina University, Greenville, NC, USA

${ }^{5}$ East Carolina University Diabetes Obesity Institute

${ }^{6}$ School of Health Sciences, University of KwaZulu-Natal, Westville Campus, Durban, S. Africa

${ }^{*}$ Corresponding author: Myers KB, Department of Nutrition Science, College of Human Ecology, East Carolina University, Greenville, NC, USA, E-mail: myersk@ecu.edu

Citation: Myers KB, Goad TN, Cox JJ, Hickner RC, Ivanescu AE, et al. (2015) Dietary Omega-3 Intakes in Southern African American and Southern Caucasian Women. J Nutr Health Sci 2(2): 204. doi:

10.15744/2393-9060.2.204

Received Date: March 20, 2015 Accepted Date: May 19, 2015 Published Date: May 21, 2015

\begin{abstract}
Given the greater incidence and severity of obesity in Southern African American (SAAW) than Southern Caucasian women (SCW), it is important to determine factors contributing to this metabolic, racial disparity. Traditional Southern foods contribute to dietary patterns high in fat. Since omega-3 fatty acids modulate the positive health aspects of dietary fat, the purpose of this study was to investigate cultural food selections providing omega-3 fatty acids in SAAW versus SCW. It was hypothesized that SAAW consume less than the recommendations for omega-3 fatty acids, and less than SCW, due to lower quality food intake. Using a validated Omega-3 Southern Food Frequency Questionnaire, SAAW and SCW dietary intakes were recorded and analyzed. Obese SCW and lean SAAW consumed below the ALA recommended amounts ( $1.04 \pm 0.57,0.95 \pm 0.64 \mathrm{~g} /$ day, respectively), while the obese SAAW consumed greater than the recommended 1.1 grams of ALA per day ( $1.25 \pm 1.02 \mathrm{~g} /$ day). The lack of lower omega- 3 intake in obese SAAW as compared to SCW indicates that a low omega-3 intake is not associated with the greater incidence of obesity in obese SAAW.

Keywords: Obesity; Race; Omega-3 fatty acids; Food frequency questionnaire

List of Abbreviations: SAAW: Southern African American Women; SCW: Southern Caucasian women; PUFA: Polyunsaturated fatty acid; HUFA: Highly unsaturated fatty acids; LA: Linoleic acid; AA: Arachidonic acid; SDA: Stearidonic acid; DPA: Docosapentaenoic acid; ALA: Alpha-linolenic acid; EPA: Eicosapentaenoic acid; DHA: Docosahexaenoic acid; FNB: Food and Nutrition Board; BMI: Body mass index; IVGTT: Intravenous glucose tolerance test; $n-3$ SFFQ: Omega-3 Southern Food Frequency Questionnaire; SPSS: Statistical Program for the Social Sciences
\end{abstract}

\section{Introduction}

Fat, a macronutrient necessary for good health, should comprise 20 to 35 percent of total energy intake [1]. Fat contributes to proper absorption and transportation of fat-soluble vitamins [2]. While all fats play an important role in metabolism, polyunsaturated fatty acids (PUFAs) are essential and have additional health benefits in addition to being a bioenergetic substrate. Omega-3 and omega- 6 fatty acids are the two main classes of PUFAs found in the Western diet. Omega- 6 PUFAs, primarily in the form of linoleic acid, obtained from vegetable oils, processed foods, nuts, eggs and meats, are converted to arachidonic acid, which leads to proinflammatory and prothrombotic eicosanoids. In contrast, increased consumption of foods high in omega- 3 fatty acids have been associated with a decrease in blood triacylglycerol and total cholesterol levels [3]. There is a large body of evidence indicating that omega-3 fatty acids elicit health benefits due to their anti-inflammatory effects in cardiovascular disease, cancer, arthritis, obesity, and other metabolic disorders, such as insulin resistance [4]. Furthermore, reduced adiposity associated with increased consumption of omega-3 fatty acids decreases the risk of co-morbidities including heart failure, hypertension, coronary artery disease, depression, type II diabetes, cancer, hypercholesterolemia, and stroke $[2,5]$. There are three primary forms of omega-3 fatty acids: alpha-linolenic acid (ALA), eicosapentaenoic acid (EPA), and docosahexaenoic acid (DHA) [6]. Omega-3 fatty acids are obtained from canola oil, flaxseed (linseed), walnuts, fatty fish such as anchovies, bluefish, salmon, tuna, trout and functional eggs (omega-3 enriched eggs). Consumption of oily fish can provide up to 3 grams of DHA and EPA per serving [5,7,8]. Current dietary recommendations in the United States for omega-3 fatty acids are 1.1 grams per day for women and 1.6 grams per day for men, based on ALA consumption [9,10]. Achieving recommended levels of omega-3 PUFA is suggested to maintain optimal health and reduce the risk of diet induced metabolic diseases [8]. As a metabolic pathway, the conversion of ALA to EPA and DHA is an inefficient method [11,12]. Therefore, in order to impart the benefits of omega-3 fatty acids, it is necessary to consume EPA and DHA via dietary sources $[8,13]$. 
The average American diet does not contain adequate levels of omega-3 fatty acids. It has been estimated that Americans consume only 23 milligrams of omega-3 fatty acids per day [14]. Socioeconomic changes over the last 150 years have caused a noticeable increase in saturated fat consumption and a decrease in omega-3 fatty acids. Deep-frying fish can alter the amount of omega-3 fatty acid present in the final food product [15]. Food manufacturing has led to foods naturally high in omega-3 fatty acids to lose part of their omega-3 content due to changes in nutritional composition of animal feed. Farmed fish, while not as high in longchain omega-3 PUFA as their wild counterpart, can still be consumed as a reasonable source of omega-3 PUFA.

Dietary differences have been linked to geographic location [3]. When compared to the rest of the United States, a typical Southern diet is energy-dense and lacks fruits, vegetables, and essential nutrients, including omega-3 fatty acids [16,17]. Race and culture are linked to typical eating patterns. Caucasian adults have reported consuming more fat from salad dressing and cheese compared to African American adults who consume fat primarily from fried chicken, sausage, and salty snacks [16]. Southern African Americans in the Lower Mississippi Delta have reported consuming less grains, vegetables, and milk products than Caucasians living in the same area, contributing to an overall poor diet [18].

Because of the reported health benefits of omega-3 fatty acid consumption, the purpose of this study was to compare the dietary omega-3 fatty acid intakes from food selections of Southern African American Women (SAAW) and Southern Caucasian Women (SCW), and to compare these intakes to the recommended intake (1.1 grams per day ALA) $[9,10]$ to determine on a racial level if omega-3 fatty acid intakes in the South are reaching optimal health benefit levels. Furthermore, we explored the possibility for a link between omega-3 dietary consumption and body mass index classification among SAAW. Although intake of omega-3 fatty acids is likely lower in SAAW than SCW women due to dietary choices, studies making these comparisons have not been conducted. Therefore, it was hypothesized that SAAW consume less than the dietary recommendations for omega-3 fatty acids and that those levels are lower than those consumed by SCW.

\section{Methods and Materials}

A total of 57 individuals ( $\mathrm{SAAW} \mathrm{N}=32, \mathrm{SCW} \mathrm{N}=25$ ) were evaluated from a small Southern coastal community to participate in this study. A personal history form was used to assess inclusion and exclusion criteria and contained questions regarding medical history, family history, tobacco use, weight, nutrition, physical activity, alcohol use, sleeping habits, education, and current family physician. The activity questionnaire recorded participants' usual activity level and was corroborated by $\mathrm{VO}_{2}$ peak measurements.

Inclusion criteria included being female, between the ages of 25 and 45, pre-menopausal, non-diabetic (fasting glucose less than or equal to $7.0 \mathrm{mmol} / \mathrm{l}$ ), non-Hispanic, and non-Asian women. Individuals were excluded from the study if they were ill or currently taking medications that affect metabolism, breast-feeding, diagnosed with diabetes, history of heart disease or kidney disease, currently smoke, pregnant, exercising regularly (more than 30 minutes per week) within the last 6 months, participating in a dietary program within the previous 6 months, and African-Americans or Caucasians not of at least second generation descent (verified by questionnaire and interview). The University Medical Committee Institutional Review Board at East Carolina University approved all protocols and procedures for this study. The selected individuals completed an informed consent form before participating in the study. The questionnaires were administered in a private setting in our clinical laboratory. All participants were tested for body composition by DEXA (TrueOne 2400 metabolic measuring system) and aerobic fitness status ( $\mathrm{VO}_{2}$ peak) using an incremental treadmill test; open circuit gas analysis of the expired air was performed with a Parvo Medics indirect calorimeter cart (Sandy, UT) prior to the data collection (data not reported). All subjects demonstrated $\mathrm{VO}_{2}$ peak values within normative values for their respective age groups; no racial group differences were noted and data was corroborated by an activity questionnaire. The method used to collect baseline dietary information was a three day food record. A kinesiology staff member, trained by a Registered Dietitian Nutritionist, administered the food record questionnaire and entered the food record data into the Nutritionist Pro software program (2007). All participants were provided with detailed instructions for completing the three day food records and were given measuring cups and utensils to assist with measuring and recording their food intake. All participants were told to eat their "normal" diets during the three day recording period. The Registered Dietitian Nutritionist analyzed the data and transposed all data into the Statistical Package for the Social Sciences (SPSS), version 20.0. Participants in the two groups were then matched for total energy and nutrient intake.

Data collection instruments included a validated omega-3 southern food frequency questionnaire (SFFQ), including 150 food items, to determine food consumption of women living in the South [19]. The omega-3 SFFQ was designed by a Registered Dietitian Nutritionist and used to identify dietary omega-3 PUFA sources consumed over the previous month. The omega-3 SFFQ used was an adaptation from a FFQ designed by Waltz-Hill [20]. Food categories included: seafood and fish, meat, eggs, dairy products, vegetables, fruits and fruit juices, nuts and seeds, grains and grain products, fats and oils, beans and legumes, and herbs and spices.

All study data were analyzed using an unpaired t-test with race or level of obesity as the independent variables. Lean versus obese comparisons was also conducted using unpaired t-tests. The estimated daily dietary omega-3 fatty acid intakes were calculated using Food Processor version 10.5.0, Microsoft Excel 2008 for Mac version 12.3.1, and were analyzed using SPSS version 20.0. Statistical significance for group mean differences was set a priori at $\mathrm{p}<0.05$. 


\section{Results}

A total of 33 Southern female participants met the study's inclusion criteria from the initial participant pool of 57 evaluated subjects. Participants' demographic characteristics are presented in Table 1. The mean age of participants was 32.97 ( \pm 7.19 ) years. There were 20 (58.8\%) SAAW and 13 (38.2\%) SCW participants. The distributions in BMI grouping among the subjects were $41 \%$ lean and $53 \%$ obese.

\begin{tabular}{|c|c|}
\hline Indicator & Frequency $(\%)$ or Mean $( \pm$ SD) \\
\hline \multicolumn{2}{|l|}{ Age } \\
\hline AAW Lean & $33.00( \pm 7.75)$ \\
\hline AAW Obese & $34.27( \pm 6.02)$ \\
\hline CW Lean & $35.33( \pm 7.06)$ \\
\hline CW Obese & $27.71( \pm 7.14)$ \\
\hline \multicolumn{2}{|l|}{ Race } \\
\hline Lean AAW & $9(27 \%)$ \\
\hline Obese AAW & $11(33 \%)$ \\
\hline Lean CW & $6(18 \%)$ \\
\hline Obese CW & $7(21 \%)$ \\
\hline \multicolumn{2}{|l|}{ BMI } \\
\hline Lean AAW & $24.30( \pm 1.87)$ \\
\hline Obese AAW & $35.92( \pm 5.34)$ \\
\hline Lean CW & $23.84( \pm 2.47)$ \\
\hline Obese CW & $37.15( \pm 3.89)$ \\
\hline \multicolumn{2}{|l|}{ AAW Education $(n=12)^{*}$} \\
\hline High School Graduate & $3(25 \%)$ \\
\hline 2-year College & $3(25 \%)$ \\
\hline 3-year College & $3(25 \%)$ \\
\hline College Graduate & $2(16.7 \%)$ \\
\hline Post Graduate & $1(8.3 \%)$ \\
\hline \multicolumn{2}{|l|}{ CW Education $(\mathbf{n}=10)^{*}$} \\
\hline High School Graduate & $3(30 \%)$ \\
\hline 2-year College & $2(20 \%)$ \\
\hline 3-year College & $1(10 \%)$ \\
\hline College Graduate & $4(40 \%)$ \\
\hline Post Graduate & $0(0 \%)$ \\
\hline
\end{tabular}

${ }^{\star}$ Not all participants reported education levels. SAAW $=$ Southern African American Women; SCW = Southern Caucasian Women. BMI: Body mass index

Table 1: Demographic Information $(\mathrm{n}=33)$

Based on data collected from the $n-3$ SFFQ, the dietary sources of omega- 3 fatty acids consumed most often within the past month were identified. Table 2 depicts the lean and obese SAAW's dietary intake of omega-3 and omega- 6 fatty acids compared to obese and lean SCW. While the mean total dietary omega-3 for the 11 obese SAAW (1.46 \pm 1.02$)$ was higher than the recommended intake of ALA (1.1 grams per day), the effect was not statistically significant. This outcome differed from the hypothesis that obese SAAW's intake of dietary omega-3 PUFAs would be lower on average than the recommended intake of ALA.

There were no statistical differences in consumption of total omega-3 PUFAs in obese SAAW $(1.46 \pm 1.02 \mathrm{~g} /$ day, $\mathrm{n}=11)$ than in lean SAAW $(\mathrm{n}=9)(1.24 \pm 0.89, \mathrm{n}=9)(\mathrm{t}=-0.50, \mathrm{p}=0.63)$, Table 2 . The findings therefore rejected the hypothesis that there would be a difference in dietary omega-3 fatty acid consumption between lean and obese SAAW. However, on average, lean SAAW's $(n=9)$ total dietary intake of omega-3 fatty acids $(1.24 \pm 0.89)$ was lower than the obese SAAW's $(n=11)$ total dietary intake of omega-3 fatty acids $(1.46 \pm 1.02)$ even though the lean SAAW's dietary intake of EPA and DHA was higher than the obese SAAW (EPA $0.09 \pm 0.13 ; 0.07 \pm 0.06$; DHA $0.16 \pm 0.21 ; 0.12 \pm 0.1$, respectively), Table 2 . EPA was the least consumed omega-3 PUFA in the lean and obese SAAW participating in the study. The sources of EPA consumption were primarily from seafood (specifically shrimp, tuna, and salmon) and chicken, Table 5. Obese SCW had the highest total omega-3 intake (2.24 \pm 0.58$)$, Table 2. 


\begin{tabular}{|c|c|c|c|c|}
\hline & $\begin{array}{c}\text { Obese AAW }(\mathbf{n}=\mathbf{1 1}) \\
\text { Mean }( \pm \mathbf{S D})\end{array}$ & $\begin{array}{c}\text { Obese CW }(\mathbf{n}=\mathbf{6}) \\
\text { Mean }( \pm \mathbf{S D})\end{array}$ & $\begin{array}{c}\text { Lean AAW }(\mathbf{n}=\mathbf{9}) \\
\text { Mean }( \pm \text { SD })\end{array}$ & $\begin{array}{c}\text { Lean CW }(\mathbf{n}=7) \\
\text { Mean }( \pm \text { SD })\end{array}$ \\
\hline Total $n-3$ & $1.46( \pm 1.02)$ & $2.24( \pm 0.58)$ & $1.24( \pm 0.89)$ & $1.38( \pm 0.86)$ \\
\hline ALA & $1.25( \pm 1.02)$ & $1.04( \pm 0.57)$ & $0.95( \pm 0.64)$ & $1.12( \pm 0.59)$ \\
\hline EPA & $0.074( \pm 0.06)$ & $0.06( \pm 0.04)$ & $0.10( \pm 0.13)$ & $0.09( \pm 0.13)$ \\
\hline DHA & $0.12( \pm 0.11)$ & $0.13( \pm 0.06)$ & $0.20( \pm 0.23)$ & $0.16( \pm 0.21)$ \\
\hline Total $n-6$ & $7.08( \pm 5.54)$ & $8.48( \pm 4.25)$ & $5.27( \pm 2.35)$ & $9.62( \pm 8.04)$ \\
\hline Linoleic acid (LA) & $6.91( \pm 5.48)$ & $8.30( \pm 4.22)$ & $5.05( \pm 2.19)$ & $8.43( \pm 8.86)$ \\
\hline Arachidonic Acid (AA) & $0.14( \pm 0.66)$ & $0.014( \pm 0.04)$ & $0.16( \pm 0.14)$ & $0.14( \pm 0.09)$ \\
\hline Other $n-6$ & $0.04( \pm 0.31)$ & $0.04( \pm 0.01)$ & $0.06( \pm 0.06)$ & $0.05( \pm 0.06)$ \\
\hline
\end{tabular}

Table 2: Daily Omega-3 and Omega-6 PUFA Intakes (g/d) by Race and Body Mass Index ( $\mathrm{n}=33$ )

\begin{tabular}{|c|c|}
\hline SAAW & SCW \\
\hline \multicolumn{2}{|l|}{ Seafood and fish } \\
\hline 1. Shrimp & 1. Shrimp \\
\hline 2. Salmon & 2. Salmon \\
\hline 3. Tuna & 3. Tuna \\
\hline \multicolumn{2}{|l|}{ Meat } \\
\hline 1. Chicken & 1. Chicken \\
\hline 2. Beef & 2. Beef \\
\hline 3. Turkey & 3. Turkey \\
\hline \multicolumn{2}{|l|}{ Eggs } \\
\hline 1. Regular eggs & 1. Egglands Best \\
\hline 2. Egglands Best & 2. Regular Eggs \\
\hline \multicolumn{2}{|l|}{ Dairy } \\
\hline 1. Cheddar cheese & 1. Cheddar cheese \\
\hline 2. Mozzarella cheese & 2. Mozzarella cheese \\
\hline 3. $2 \%$ milk & 3. Yogurt, skim milk, $2 \%$ milk, Swiss cheese \\
\hline \multicolumn{2}{|l|}{ Fruits and fruit juices } \\
\hline 1. Banana & 1. Banana \\
\hline 2. Apple juice & 2. Cranberry juice \\
\hline 3. Strawberries & 3. Apple \\
\hline \multicolumn{2}{|l|}{ Nuts and seeds } \\
\hline 1. Walnut & 1. Sunflower seed \\
\hline 2. Pecan & 2. Pecan \\
\hline 3. Ground flaxseed & 3. Pistachio \\
\hline \multicolumn{2}{|l|}{ Breads/cereals/grains } \\
\hline 1. Biscuit & 1. Whole wheat bread \\
\hline 2. Whole wheat bread & 2. Biscuit, white bread \\
\hline 3. White bread & 3. Cornbread \\
\hline \multicolumn{2}{|l|}{ Fats and oils } \\
\hline 1. Canola oil, butter & 1. Olive oil \\
\hline 2. Miracle Whip & 2. Canola oil \\
\hline 3. Olive oil, margarine & 3. Butter \\
\hline \multicolumn{2}{|l|}{ Legumes and products } \\
\hline 1. Pinto beans & 1. Pinto beans \\
\hline 2. Peanut butter & 2. Peanut butter \\
\hline 3. Baked beans & 3. Red kidney beans, lima beans \\
\hline \multicolumn{2}{|l|}{ Herbs and spices } \\
\hline 1. Black pepper & 1. Black pepper \\
\hline 2. Basil & 2. Cayenne pepper, garlic cloves \\
\hline 3. Ginger & 3. Rosemary, basil, paprika \\
\hline
\end{tabular}

Table 5: Rank Order of Omega-3 Fatty Acids Food Sources by Food Group ( $\mathrm{n}=33)$ 
The top 3 consumed omega-3 fatty acid foods for each food category, based on data collected from the omega-3 SFFQ, for both SAAW and SCW, are presented in Table 5. The participants' choice of seafood and fish, meat and dairy were the same for both groups of women, whereas the remaining food categories varied. The three day food records were used to calculate estimated usual caloric and macronutrient intake for all participants (Table 6). The caloric and macronutrient intakes for this sample varied greatly between the lean SAAW and SCW. Variations in food preparation and selection preferences may have influenced total caloric intakes for these sample populations.

\begin{tabular}{|c|c|c|c|c|}
\hline & $\begin{array}{c}\text { Obese AAW }(\mathbf{n}=\mathbf{1 1}) \\
\text { Mean }( \pm \text { SD) }\end{array}$ & $\begin{array}{c}\text { Obese CW }(\mathbf{n}=\mathbf{6}) \\
\text { Mean }( \pm \text { SD) }\end{array}$ & $\begin{array}{c}\text { Lean AAW }(\mathbf{n}=\mathbf{9}) \\
\text { Mean }( \pm \text { SD) }\end{array}$ & $\begin{array}{c}\text { Lean CW }(\mathbf{n}=7) \\
\text { Mean }( \pm \text { SD) }\end{array}$ \\
\hline Calories & $2272.16( \pm 836.95)$ & $2104.84( \pm 535.36)$ & $1683.59( \pm 540.79)$ & $2147.85( \pm 468.33)$ \\
\hline Total Fat $(\mathbf{g})$ & $89.29( \pm 38.12)$ & $77.84( \pm 25.53)$ & $61.86( \pm 18.16)$ & $80.07( \pm 40.11)$ \\
\hline Monounsaturated Fatty Acids $(\mathbf{g})$ & $19.96( \pm 10.68)$ & $17.98( \pm 8.25)$ & $18.13( \pm 7.25)$ & $22.91( \pm 13.29)$ \\
\hline Polyunsaturated Fatty Acids $(\mathbf{g})$ & $12.35( \pm 7.08)$ & $7.13( \pm 2.95)$ & $8.99( \pm 4.04)$ & $11.19( \pm 5.75)$ \\
\hline Saturated Fatty Acids $(\mathbf{g})$ & $24.79( \pm 10.60)$ & $24.95( \pm 10.64)$ & $19.04( \pm 8.16)$ & $25.47( \pm 16.93)$ \\
\hline Trans Fatty Acids $(\mathbf{g})$ & $2.94( \pm 2.38)$ & $3.90( \pm 3.85)$ & $1.41( \pm 1.32)$ & $1.37( \pm 2.01)$ \\
\hline Protein $(\mathbf{g})$ & $84.83( \pm 45.18)$ & $74.24( \pm 24.58)$ & $83.23( \pm 42.09)$ & $83.40( \pm 36.54)$ \\
\hline Carbohydrates $(\mathbf{g})$ & $294.63( \pm 110.87)$ & $289.14( \pm 70.01)$ & $206.41( \pm 70.05)$ & $275.75( \pm 52.76)$ \\
\hline
\end{tabular}

Table 6: Caloric and Macronutrient Intake Based on Three Day Food Records ( $n=33$ )

All SAAW participants' $(\mathrm{n}=20)$ dietary omega-3 fatty acid intakes are compared to all S SCW participants' $(\mathrm{n}=13)$ intakes in Table 3. The daily mean dietary intake of SAAW (1.36 \pm 0.95$)$ was 0.05 grams per day higher than that of SCW (1.31 \pm 0.68$)$ (two independent sample $\mathrm{t}$ test $\mathrm{t}=0.19, \mathrm{t}=0.85$ ). This finding was not statistically significant and rejected the hypothesis that dietary PUFA intake of SAAW would be different than that of SCW. All participants in this study combined consumed the United States recommended amounts of omega-3 fatty acids, based on ALA. EPA and DHA consumptions were low and suggest a need for more dietary sources of these specific fatty acids.

\begin{tabular}{|c|c|c|}
\hline Indicator & $\begin{array}{c}\text { AAW }(\mathbf{n}=20) \\
\text { Mean }( \pm \text { SD })\end{array}$ & $\begin{array}{l}\text { CW }(\mathbf{n}=\mathbf{1 1}) \\
\text { Mean }( \pm \text { SD })\end{array}$ \\
\hline Total $n-3$ & $1.36( \pm 0.95)$ & $1.31( \pm 0.68)$ \\
\hline ALA & $1.11( \pm 0.86)$ & $1.08( \pm 0.55)$ \\
\hline EPA & $0.09( \pm 0.09)$ & $0.08( \pm 0.09)$ \\
\hline DHA & $0.16( \pm 0.17)$ & $0.15( \pm 0.14)$ \\
\hline Total $n-6$ & $6.27( \pm 4.40)$ & $9.00( \pm 5.94)$ \\
\hline Linoleic acid (LA) & $6.07( \pm 4.33)$ & $8.36( \pm 6.35)$ \\
\hline Arachidonic Acid (AA) & $0.15( \pm 0.11)$ & $0.14( \pm 0.06)$ \\
\hline Other $n-6$ & $0.05( \pm 0.05)$ & $0.04( \pm 0.04)$ \\
\hline
\end{tabular}

*The $\mathrm{n}$ value for Table 3 does not equal 33 due to missing data

Table 3: Omega-3 and Omega- 6 Daily Intakes $(\mathrm{g} / \mathrm{d})$ by Race $(\mathrm{n}=31)$

Mean daily consumption of total dietary omega-3 fatty acids of all participants are presented in Table 4. Total dietary ALA fatty acid intakes averaged above the recommended amount of 1.1 grams per day, which approximates 82.7 percent of the participants' total dietary omega-3 fatty acid intake. Dietary EPA contributed the least to all participants' daily omega-3 intakes (5.8\%). Total dietary omega-3 fatty acid intakes ranged from 0.282 to 3.898 grams per day.

\begin{tabular}{|c|c|}
\hline & Mean $( \pm$ SD) \\
\hline Total $n-3$ & $1.39( \pm 0.88)$ \\
\hline ALA & $1.15( \pm 0.80)$ \\
\hline EPA & $0.08( \pm 0.09)$ \\
\hline DHA & $0.15( \pm 0.16)$ \\
\hline Total $n-6$ & $7.42( \pm 5.11)$ \\
\hline Linoleic acid (LA) & $7.08( \pm 5.19)$ \\
\hline Arachidonic Acid (AA) & $0.14( \pm 0.09)$ \\
\hline Other $n-6$ & $0.04( \pm 0.04)$ \\
\hline
\end{tabular}

${ }^{*}$ The $n$ value for Table 4 does not equal 33 due to missing data

Table 4: Omega-3 and Omega- 6 Daily Total Intakes (g/d) for All Participants $(\mathrm{n}=32)$ 


\section{Discussion}

To our knowledge, this is the first study exploring cultural food selections in SAAW versus SCW to assess dietary intakes of omega-3 fatty acids (recommendation as 1.1 grams of ALA). The mean total dietary ALA intake of all participants in the study exceeded the recommended amount although the large standard deviations suggest a widely varied dietary intake among all participants. When assessing differences in total omega-3 fatty acid consumption (via diet evaluation) ALA, EPA and DHA are typically included. ALA is a limiting factor in dietary omega-3 consumption because it must be converted to EPA and DHA to meet the body's demand for omega-3 fatty acids. As this conversion of ALA to EPA and DHA is not an efficient process, it is imperative that EPA and DHA be consumed via dietary sources [11,12]. Dietary sources of EPA and DHA are very limited to specific food items, which leads to low dietary consumption depending on the geographical region and dietary preferences. Given the current study's geographic location, seafood intake is popular during certain seasons. The main ALA containing foods consumed among this study's participants included walnuts, canola oil, flaxseed (linseed), soybeans, broccoli, whole wheat bread, and cheddar cheese, whereas the main EPA/DHA containing foods consumed were shrimp, tuna, salmon, and chicken. Even if one meets the ALA recommendation, the body must undergo the inefficient conversion process to EPA and DHA. In a population where seafood is a staple, it is imperative to consider EPA and DHA recommendations, which currently are not established [11,21].

We also observed that the lean SAAW consumed below the ALA recommendations 0.95 \pm 0.64 ), while the lean SCW consumed the recommended amount (1.12 \pm 0.59$)$. McCabe-Sellars et al. [18] also investigated dietary variations between SAAW and SCW living within a Southern community. McCabe-Sellars [18] did not focus on a particular macronutrient, but rather investigated the overall diet and concluded that African Americans' dietary intakes were poor overall compared to Caucasians. Therefore, lean SAAW may benefit from selecting more nutrient dense foods that contain omega-3 fatty acids.

It is established that obesity continues to rise in the United States [9], that there is a higher incidence of obesity among SAAW than SCW [22], and that Southern diets do not contain adequate amounts of dietary omega-3 fatty acids [16,17]. The current study was conducted to determine if dietary patterns differed between the SAAW and SCW, and whether these differences were also related to obesity status. We observed that the omega-3 SFFQ analysis demonstrated variations in dietary omega-3 fatty acid intakes among the participant groups despite there being no statistically significant difference in the diets of SAAW and SCW living in this Southern Coastal community. This study had a small number of participants in each of the groups which may explain the failure to find a statistical difference between the groups. The obese SAAW participating in this study actually consumed greater than the recommended 1.1 grams of ALA per day, while the obese SCW consumed below the recommendation $(1.25 \pm 1.02,1.04 \pm 0.57$, respectively). The difference in obese SAAW and SCW intake of omega-3 may be due to lower intake of total calories by the obese SCW and the different composition of total calories. This indicates that food selection, preference and possibly cooking/food preparation methods may contribute to the distribution of nutrients and caloric intakes by race and region.

The method of food preparation also has an impact on the nutritional content of the food when consumed. Consuming fried-fish decreases the nutritional content and can add omega- 6 fatty acids and trans fats to the food item, which decreases its nutritional value. By providing nutrition education to individuals living in this region, they may be able to decrease their dietary intake of these identified unhealthy fats by modifying their cooking techniques.

Similar to the current study, Lovejoy et al. [23] observed SAAW's dietary intakes of PUFAs to be higher than that of SCW. The SAAW consumed significantly more arachidonic acid, an n-6 PUFA, and EPA than the SCW. The predominant sources of arachidonic acid were chicken, turkey, and eggs. Also similar to the current study, the subject's EPA dietary intakes were mainly from fish; specifically, trout, salmon, and catfish. As demonstrated by Lovejoy et al. and the current study, location is a key factor in determining individuals' dietary preferences and to varying dietary patterns. While fish consumption tends to be increased along the coastal regions, it is much less in other areas across the country, specifically in land-locked regions.

It is important to acknowledge certain limitations of this study. We did not measure food preparation methods which are known to influence the biological value of omega fatty acids available from the diet. For future studies, it would be beneficial for individuals to specify preparation methods of pertinent omega-3 PUFA-rich foods. With this information, it could be determined whether the individuals are truly obtaining the complete omega-3 PUFA health benefits. Secondly, since the omega- 6 fatty acid consumptions were calculated using the omega-3 SFFQ, which was designed using identified omega-3 containing foods, the omega-6:omega-3 ratio was not calculated as it would under-report omega- 6 consumption. We did analyze omega- 6 intake from the foods reported on the omega-3 SFFQ, and there were no significant differences in omega-6 between SAAW and SCW (Table 3). These omega- 6 fatty acid data; however, are most likely an underrepresentation of total omega- 6 consumption because the questionnaire was not designed for that purpose. Therefore, future studies should also investigate potential differences in regional consumption of omega-6 PUFA to determine if this is an important variable influencing the incidence and severity of obesity and related metabolic disease in regions of the United States similar to the one reported in the present study.

\section{Conclusion}

In conclusion, the purpose of the present study was to compare omega-3 PUFA consumption between SAAW and SCW in a rural, coastal region of the United States that is particularly high in incidence of obesity and Type-2 Diabetes. The major impact of this research study was that while it is perceived in the literature that SAAW consume less omega-3 PUFAs that contributes to higher incidence of Obesity and Type 2 Diabetes, this may not be the case when examining particular regions in the United States. This 
study has a broad scope in that the findings suggest topics in need of future research, including how food preparation methods effect omega-3 content of foods consumed and overall consumption of specific omega-3 fatty acids.

\section{Acknowledgement}

This study was supported by The National Institutes of Health RO1-DK075880 (R.N. Cortright). We want to thank the students and laboratory staff that helped with the management and data collection for this study.

\section{References}

1. Centers for Disease Control and Prevention: Nutrition for everyone - Dietary Fat (2002) Accessed September 9, 2012.

2. Di Pasquale MG (2009) The essentials of essential fatty acids. J Diet Suppl 6: 143-61.

3. National Center for Health Statistics (2012) Health, United States, 2011: With Special Feature on Socioeconomic Status and Health. Hyattsville, MD.

4. Torres IC, Mira L, Ornelas CP, Melim A (2000) Study of the effects of dietary fish intake on serum lipids and lipoproteins in two populations with different dietary habits. Br J Nutr 83: 371-9.

5. Institute of Medicine of the National Academics (2002) Accessed February 9, 2012.

6. Gomez-Candela C, Bermejo-Lopez LM, Loria-Kohen V (2011) Importance of a balance omega 6/omega 3 ratio for the maintenance of health: Nutritional recommendations. Nutr Hosp 26: 323-9.

7. Sanders TAB (2010) The role of fat in the diet - quantity, quality and sustainability. Nutr Bull 35: 138-46.

8. Siriwardhana N, Kalupahana NS, Moustaid-Moussa, N (2012) Health benefits of n-3 polyunsaturated fatty acids: Eicospentaenoic acid and Docosahexaenoic acid. Adv Food Nutr Res 65: 211-22.

9. Food and Nutrition Board (2005) Dietary Reference Intakes for energy, carbohydrates, fiber, fat, protein, and amino acids (Macronutrients), The National Academies Press, Washington, DC, USA.

10. National Research Council (2005) Dietary reference intakes for energy, carbohydrate, fiber, fat, fatty acids, cholesterol, protein, and amino acids (Macronutrients), The National Academies Press, Washington, DC, USA.

11. Komprda T (2012) Eicosapentaenoic and Docosahexaenoic acids as inflammation-modulating and lipid homeostasis influencing nutraceuticals: A review. J Funct Food 4: 25-38.

12. Sayanova O, Napier JA (2011) Transgenic oilseed crops as an alternative to fish oils. Prostaglandins Leukot Essent Fatty Acids 85: $253-60$.

13. Harris W (2009) Omega-6 and omega-3 fatty acids: partners in prevention. Curr Opin Clin Nutr Metab Care 13: 125-9.

14. Gazella KA (2011) Shop Smart: GOOD FAT. Better Nutrition 12: 18-21.

15. Agatston A (2009) Upping intake of omega-3s, Everyday Health, Accessed October 3, 2012.

16. Zotos A, Kotaras A, Mikras E (2013) Effect of baking sardine (Sardina pilchardus) and frying of anchovy (Engraulis encrasicholus) in olive and sunflower oil on their quality. Food Sci Technol Int 19: 11-23.

17. Tucker KL, Maras J, Champagne C, Connell C, Goolsby S, et al. (2005) A regional food-frequency questionnaire for the US Mississippi Delta. Public Health Nutr 8: 87-96.

18. McCabe-Sellers BJ, Bowman S, Stuff JE, Champagne CM, Simpson PM, et al. (2007) Assessment of the diet quality of US adults in the Lower Mississippi Delta. Am J Clin Nutr 86: 697-706

19. Ritter-Gooder PK, Lewis NM, Heidal KB, Eskridge KM (2009) Validity and reliability of a quantitative food frequency questionnaire measuring n-3 fatty acid intakes in cardiac patients in the Midwest: A validation pilot study. J Am Diet Assoc 106: 1251-5.

20. Waltz-Hill M (2000) Using multi-media nutrition education to increase consumer understanding of coronary heart disease. University of Nebraska-Lincoln $30-1$.

21. Griffin BA (2008) How relevant is the ratio of dietary n-6 to n-3 polyunsaturated fatty acids to cardiovascular disease risk? Evidence from the OPTILIP study. Curr Opin Lipidol 19: 57-62.

22. Herrick H, Akin D (2012) Trends in key health objectives for North Carolina and the nation: A report from the Behavior Risk Factor Surveillance System. Department of Health and Human Services, Division of Public Health, State Center for Health Statistics.

23. Lovejoy JC, Champagne CM, Smith SR, de Jonge L, Xie H (2001) Ethnic difference in dietary intakes, physical activity, and energy expenditure in middle-aged, premenopausal women: The health transitions study. Am J Clin Nutr 74: 90-5.

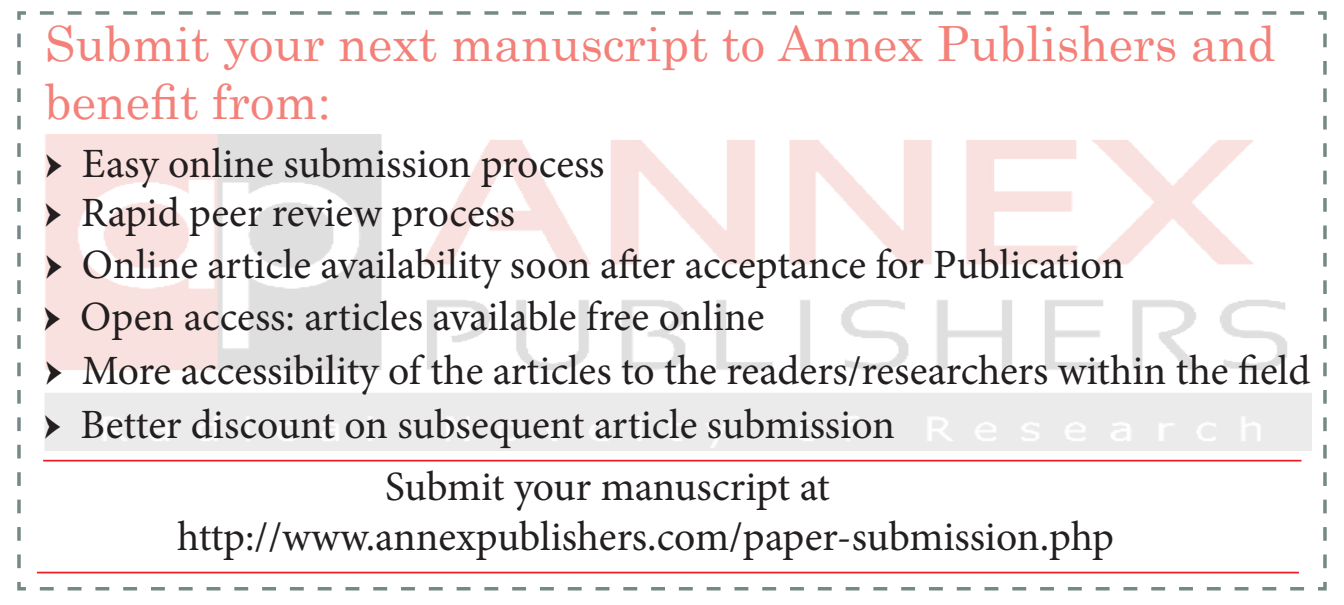

